\title{
The Effect of Spiritual Empowerment with Multimedia Educational Method on the Spiritual Health of the Cancerous Children's Family
}

\author{
Minoo Asadzandi ${ }^{*}$, Safora shahrabi farahany ${ }^{2}$, Hassan Abolghasemy ${ }^{3}$, Mohsen Saberi ${ }^{4}$ and \\ Abass Ebadi ${ }^{5}$ \\ ${ }^{1}$ Research fellow Medicine, Quran and Hadith Research Center, Anesthesiology Department, Faculty of Nursing, Baqiyatallah \\ University of Medical Sciences. Member of Founding Board, Spiritual Health Research Center, Qom University of Medical \\ Sciences, Tehran, IR Iran
}

${ }^{2}$ Pediatric Nursing, Faculty of Nursing, Baqiyatallah University of Medical Sciences, Tehran, IR Iran

${ }^{3}$ Hereditary Diseases of Blood Research Center, Shaheed Beheshti University of Medical Sciences, Department of Pediatrics, Faculty of Medicine, Baqiyatallah University of Medical Sciences, Tehran, IR Iran

${ }^{4}$ Quran and Hadith Research Center, Baqiyatallah University of Medical Sciences. Tehran, IR Iran

${ }^{5}$ Behavioral Sciences Research Center, Lifestyle institute, Nursing Faculty, Baqiyatallah University of Medical Sciences, Tehran, IR Iran

*Corresponding author: Minoo Asadzandi, Baqiyatallah University of Medical Sciences, Nursing Faculty. Sheikh Baha'i Street southern, Molla Sadra Ave. Vanak Square. Tehran, Iran

\section{ARTICLE INFO}

Received: 幽 January 08, 2021

Published: January 18, 2021

Citation: Minoo Asadzandi, Safora shahrabi farahany, Hassan Abolghasemy, Mohsen Saberi, Abass Ebadi. The Effect of Spiritual Empowerment with Multimedia Educational Method on the Spiritual Health of the Cancerous Children's Family. Biomed J Sci \& Tech Res 33(2)-2021. BJSTR. MS.ID.005367.

Keywords: Education; Empowerment; Family; Health; Neoplasms; Spirituality

\section{ABSTRACT}

Background: finding the meaning for suffering and questions about illness and dying, can create spiritual distress for cancerous children's family. This study was conducted to investigate the effect of spiritual empowerment with multimedia educational method on the spiritual health of the cancerous children's family.

Methods: This randomized, controlled, pre- and post-clinical trial was done in 2019 for 72 cancerous children's parents from the armed forces family in the Baqiyatallah hospital, and Children's Medical Center. The samples were assigned into control and intervention groups by using block randomization method. In educational support system, spiritual empowerment program based on the Sound Heart Model was provided to the intervention group for- increasing patient and family trust in God- developing relationships with God, self, people, and nature -enhancing parental knowledge -motivation. Training spiritual skills was conducted with multimedia software. Along with, training sessions were held once a week on the social network. The Paloutzian \& Ellison's spiritual health questionnaire was completed before and immediately after the intervention by parents.

Results: Comparison of mean and standard deviation of spiritual health score in two groups, by independent t-test showed that there was no significant difference between the two groups before the intervention $(p=0.771)$, but after the intervention there was a significant difference $(\mathrm{p}<0.001)$. Paired t-test also showed that there was no significant difference in the control group before and after the intervention $(p=0.024)$, while in the intervention group there was a significant difference $(\mathrm{p}<0.001)$.

Conclusion: The results showed that spiritual empowerment program based on sound heart model was effective on spiritual health of parents. The use of multimedia educational method had an impact on the ability of parents to achieving the sound heart. Regarding the impact of parental health on quality of life of sick children, spiritual empowerment is recommended. 


\section{Introduction}

Cancer is cells disease, characterized by an unlimited and uncontrolled proliferation of cells that form malignant neoplasm [1]. According to the World Health Organization (WHO) report, an increase is expected in the number of cancerous children, from 10 million in 2000 to 15 million in 2020, that sixty percent of them belong to the least developed countries [2]. Today the number of children with cancer are 15 out of every 100,000 children in year [3] which threatens child's life [4]. Cancer causes problems for patient and family due to the chronic nature of disease, its signs and symptoms, the long-term treatment with chemotherapy and the side effects of the treatment [5]. In the meantime finding the meaning for suffering constitute the core of the cancerous children's life [6]. They have important philosophical questions when becoming aware of their illness. They ask their parents: Why am I sick? Why am I sick among relatives children? Why did bad things happen to me? Why have I got the disease? What is the cause of my pain and suffering? How am I going to die? What will happen after death? Will I see you from that world? How is paradise and hell? Why has God made me sick? Why has God suffered me? [7].

Concurrent with the illness, the spiritual distress of the child is accelerated. The need for meaning and purpose arises to deal with the disease crisis [8]. If the parents cannot answer these questions, the child and parents will suffer from spiritual distress [9]. Spiritual distress manifested problems in children like: anxiety, depression, abnormal pain, crying, sadness, lack of control over thinking and emotions, feeling abandoned and lonely, guilty feeling, anger and aggression, denial, despair, helplessness, self-destruction, powerless feeling, hopeless, irritability, energy deficiency and doubting about God [10] and causes problems in parents such as: anxiety, depression, guilt feeling, post-traumatic stress disorder (PTSD), reduced levels of health, adjustment disability, financial and occupational problems, impaired family relationships and marital relationships, care burden [11].

Parental distress arises from: lack of awareness about the cause of cancer, unfamiliarity with the treatment and care methods, high cost of treatment, economic consequences, suffering imposed on the child during illness, separation from the child, altered physical condition of sick child, the symptoms of the disease and the side effects of treatment, which lead to undesirable effects on child treatment [12] and damages the bio-psycho- socio-spiritual health of the patient and family. In this situation parents desperately need support [13]. On the other hand, according to the home care approach in pediatric oncology, children are dependent on the family for care and parents, especially mothers, play an active role in child care and treatment [14]. They also fear from the consequences of the disease and worry about the child future life [15]. They suffer from: anxiety, depression, denial, anger depending on their culture and beliefs [16]. So strengthening family members' abilities by empowerment program is the goal of nursing interventions in family-centered care to overcome problems [17].
Empowerment is a dynamic, positive, interactive, and social process that improves patient and family's quality of life, improves accountability, better interaction with health authorities, prevents complications, decreases costs of treatment, and creates satisfaction by positive view and better response to treatment and disease [18]. For this reason, in recent years the concept of family empowerment in nursing and medical research has gained a special place and is referred as the necessity of the nursing profession [19]. Since the chronic diseases impairs self-esteem, coping mechanisms and communication ability, causes spiritual crisis in patient and the family, spiritual empowerment should be considered [20]. Because in all cultures, people in critical situations and when illness threatens their lives, seek help from a divine source [21]. Spirituality through the relationship with God creates values and beliefs in the family and gives meaning to life, empowers the family [22]. Today, the healing effects of spirituality are not hidden, so the World Health Organization (WHO) considers paying attention to patients' beliefs as an important factor in healing and recovery [23].

Faith in God enables people to cope with various crises. So, the model- based education should be consider for improving the patient and family attitudes and increasing their self-efficacy as the goals of nursing care [24]. The care model should be consistent with patient and family culture and beliefs. The "Spiritual Care Model of Sound Heart ", based on the religious spirituality of the Abrahamic religions, emphasizes self-care and home care [25]. The goal of spiritual care in model is achieving a Sound heart (a calm and safe soul, full of trust, love, hope, joy, security, satisfaction of fate, pleasure, patience, happiness, optimism, without future anxiety, as well as regret and sorrow) by development the relationship with God, others, Self and nature [26]. In patient and family-centered approach, with community-based care, uses the assistance and participation of the patient and family in care. For outpatients, provides counseling and spiritual skills training in an educational support system [27]. Model by increating selfawareness (understanding the person's thoughts, intentions and emotional states), benefiting from nature and communicating with friends and creating a social- support network helps family for emotional adaptation [28]. This study was conducted to investigate the effect of spiritual empowerment based on Sound Heart Model with multimedia educational method on the spiritual health of the cancerous children's family.

\section{Methods}

This randomized, controlled, pre- and post-clinical trial was conducted in 2019 for the cancerous children's parents from the armed forces family. Referred parents to the Baqiyatallah hospital, and Children's Medical Center, who were willing to participate in the research were selected according to the inclusion criteria: being able to communicate and complete the questionnaire, being familiar with Persian language, without a history of: -addiction, -chronic mental illness, -taking psychiatric drugs, -participating in the similar research, - having other critical ill children. 
In a meeting with the researcher, after explaining the research objectives and emphasizing on the confidentiality of any personal information that would lead to disclosure of parent's identity and obtaining informed consent, all samples were completed questionnaires. Then by forming the quadruple blocks as the method of entering samples into each group, they were randomly assigned to test and control groups before intervention. The intervention was performed for the test group by donating educational software and once a week communication through the social network. The control group only received routine care. At the end of the intervention, the questionnaires were completed by both groups and the results were compared. The educational software was also donated to the control group and its questions were answered. The sample size was calculated (with $\alpha=5 \%$ and power $=90 \%$ ), by using the mean and standard deviation obtained from a similar study and Altman's Nomo gram [29].

Sample size in each group with $10 \%$ loss, were determined 36. Data were collected by: 1- demographic questionnaire (12 questions) includes two parts: A: Caregiver information such as: age, sex, marriage, education, family relationship and illness B: Patient information such as: duration of illness, type of cancer, ability to perform personal tasks, the amount of care needed. 2-The Paloutzian \& Ellison's spiritual health questionnaire that included 20 items in two groups of religious and existential health, each of them has 10 items and account for 10-60 score. Total score of spiritual health is 20-120. Categorizing scores included: (20-40) as low spiritual health, (41-99) average spiritual health, (100-120) high spiritual health. Validity of spiritual health questionnaire was identified and confirmed through content validity and its reliability was determined by Cronbach's alpha 0.82, indicates a good reliability of this tool [30].

Parent's education was performed according to the algorithm of the Sound heart model [28]. Training software includes: 16 PowerPoint presentations, the "Spiritual Care Guide for Patients' Family" book [9], educational clips, "animation" about cancer and its treatments with childish language, religious poetry, and wallpapers of nature with bird song. The intervention included: sixteen spiritual counseling sessions, 15-30 minutes, once a week, with emphasis on improving the relationship with God, self, people and nature according to Table 1 .

Table 1: Conceptual map of executive steps for spiritual education to achieve the Sound Heart (Spiritual Health).

\section{Spiritual counselor in the role of mentor}

Establishing "spiritual communication" and gaining patient and family trust

Creating the courage to face the crisis caused by the disease Reducing the perceived threat $\quad$ Relieving grief from illness Developing a relationship with God as a healer

Advising for hope and optimism to the future
Positive Thinking Training

\begin{tabular}{|c|c|}
\hline \multicolumn{2}{|c|}{ Creating spiritual self-awareness } \\
\hline $\begin{array}{c}\text { Spiritual Distresses and Spiritual } \\
\text { Care Guidelines Training }\end{array}$ & $\begin{array}{c}\text { Problem solving training and } \\
\text { emotional adjustment to illness }\end{array}$ \\
\hline \multicolumn{2}{|c|}{ Pay attention to the spirituality in the whole universe } \\
\hline $\begin{array}{c}\text { Developing social communication, } \\
\text { love and forgiveness training }\end{array}$ & $\begin{array}{c}\text { Developing a relationship with } \\
\text { nature, thanking God for blessings }\end{array}$ \\
\hline \multicolumn{2}{|c|}{ Motivating with normative beliefs and subjective norms } \\
\hline $\begin{array}{c}\text { Creating a sense of self-efficacy } \\
\text { and behavioral intention }\end{array}$ & Self-control (Self-calculation) \\
\hline
\end{tabular}

\section{Finding}

In the above Table 2, independent t-test showed that there was no significant difference between the two groups before the intervention ( $p=0.592)$, but after the intervention there was a significant difference $(\mathrm{p}=0.003)$ (Table 3$)$.

Table 2: Comparison of mean and standard deviation of spiritual health score, religious dimension, in two groups before and after intervention

\begin{tabular}{|c|c|c|c|}
\hline $\begin{array}{c}\text { Group } \\
\text { Time }\end{array}$ & Control $\mathbf{n}=\mathbf{3 6}$ & $\begin{array}{c}\text { Intervention } \mathbf{n} \\
\mathbf{3} \mathbf{3 6}\end{array}$ & Independent t-test \\
\hline Before & $31.5(3.45)$ & $32(4.74)$ & $\begin{array}{c}\mathrm{t}=-0.539 \\
\mathrm{p}=0.592\end{array}$ \\
\hline After & $44.7(8.48)$ & $50.2(6.46)$ & $\begin{array}{c}\mathrm{t}=-3.07 \\
\mathrm{p}=0.003\end{array}$ \\
\hline $\begin{array}{c}\text { Paired } \\
\mathrm{t} \text {-test }\end{array}$ & $\begin{array}{c}\mathrm{t}=-8.24 \\
\mathrm{p}<0.001\end{array}$ & $\begin{array}{c}\mathrm{t}=-13.30 \\
\mathrm{p}<0.001\end{array}$ & \\
\hline
\end{tabular}

Table 3: Comparison of mean and standard deviation of spiritual health score of existential dimensions in two groups before and after intervention.

\begin{tabular}{|c|c|c|c|}
\hline $\begin{array}{c}\text { Group } \\
\text { Time }\end{array}$ & $\begin{array}{c}\text { Control } \mathbf{n}=\mathbf{3 6} \\
\text { The mean (SD) }\end{array}$ & $\begin{array}{c}\text { Intervention } \mathbf{n} \\
\mathbf{2} \mathbf{3 6} \\
\text { The mean (SD) }\end{array}$ & $\begin{array}{c}\text { Independent } \\
\text { t-test }\end{array}$ \\
\hline Before & $47.7(6.44)$ & $47.7(6.42)$ & $\begin{array}{c}\mathrm{t}=-0.394 \\
\mathrm{p}=0.695\end{array}$ \\
\hline After & $40.69(7.80)$ & $47.47(7.16)$ & $\begin{array}{c}\mathrm{t}=3.84 \\
\mathrm{p}<0.001\end{array}$ \\
\hline $\begin{array}{c}\text { Paired } \\
\mathrm{t} \text {-test }\end{array}$ & $\begin{array}{c}\mathrm{t}=4.06 \\
\mathrm{p}<0.001\end{array}$ & $\begin{array}{c}\mathrm{t}=0.239 \\
\mathrm{p}=0.812\end{array}$ \\
\hline
\end{tabular}

Independent t-test showed that there was no significant difference between the two groups before the intervention ( $p$ $=0.985$ ), whereas after the intervention there was a significant difference ( $p<0.001)$. After the intervention time, the existential health of the control group significantly decreased ( $p<0.001$ ), while the intervention prevented the occurrence of this problem in the intervention group $(\mathrm{p}=0.812)$.

In the Table 4 above, independent t-test showed that there was no significant difference between the two groups before the intervention ( $p=0.771$ ), but after the intervention there was a significant difference ( $p<0.001)$. Paired t-test also showed that there was no significant difference in the control group before and after the intervention ( $p=0.024)$, while in the intervention group there was a significant difference $(p<0.001)$. 
Table 4: Comparison of mean and standard deviation of total spiritual health score in two groups before and after intervention.

\begin{tabular}{|c|c|c|c|}
\hline $\begin{array}{c}\text { Group } \\
\text { Time }\end{array}$ & $\begin{array}{c}\text { Control } \mathbf{n}=\mathbf{3 6} \\
\text { The mean (SD) }\end{array}$ & $\begin{array}{c}\text { Intervention } \mathbf{n}=\mathbf{3 6} \\
\text { The mean (SD) }\end{array}$ & $\begin{array}{c}\text { Independent } \\
\mathbf{t} \text {-test }\end{array}$ \\
\hline Before & $79.25(7.12)$ & $79.75(7.41)$ & $\begin{array}{c}\mathrm{t}=-0.292 \\
\mathrm{p}=0.771\end{array}$ \\
\hline After & $85.4(13.7)$ & $97.6(11.36)$ & $\begin{array}{c}\mathrm{t}=-4.12 \\
\mathrm{p}<0.001\end{array}$ \\
\hline Paired t-test & $\begin{array}{c}\mathrm{t}=-2.35 \\
\mathrm{p}=0.024\end{array}$ & $\begin{array}{c}\mathrm{t}=0.239 \\
\mathrm{p}<0.001\end{array}$ \\
\hline
\end{tabular}

\section{Discussion}

One of the concepts has introduced in medical and nursing literature in recent decades is the concept of spiritual health, as the benefits of spirituality for better coping [31]. The concept of spirituality includes an effective form of adaptation and problem solving behavior and the highest levels of growth in the various domains such as: cognitive, ethical, emotional, interpersonal which creates a general view of life and enables patients to use spiritual resources to make important decisions and solve daily problems [32]. Evidences indicate that there is a significant positive relationship between spiritual beliefs, health and life satisfaction [33] which is in line with the present study. Sherry believes that we have an "inner voice" that empowers us in the face with suffering [34]. Religious adjustment strategies empower the patient for: maintaining and enhancing the patient's self-esteem, hope, purposeful and meaningful life, increasing mental health [35], improving the patient's ability to cope with the disease, increasing the speed of recovery, and patients physical condition [36] so have positive effects on various aspects of health [37].

Given that epistemology constitutes ontology (philosophical attitude) and shapes life style and cultural aspects of societies, and answers to the philosophical questions of the cancerous children's [27]. In the empowerment program of this research, philosophical attitude and religious spirituality of Islam were used. In the paradigm of monotheistic religions based on "revelation epistemology". Muslims belief in the existence of the soul from the unseen world and the "life after death". The soul can relate man to God as a healer who heals patients. God's mercy is greater than His wrath [38]. Prayer is the way for receiving God's mercy. The healing worship can reduce the severity of patient's illness [39]. So, in this research, parents were encouraged to pray and faith therapy skills were trained: Trusting in God, Asking Help from Imams, Touching with Healing Prayer, Islamic sleep ritual was taught to parents [40] which is in harmony with Rezai's, et al. [41] that showed a relationship between the frequency of prayer and the spiritual health of cancer patients and suggested that prayer should be considered as a spiritual health promotion method [41].

Mohebbi Far, et al. [42] showed a positive and significant relationship between spiritual health and quality of life and suggested that spiritual health should be promoted as a factor in improving the quality patients' life [42]. In the chronic and lifethreatening illnesses, frustration of God's mercy causes fear and anxiety from the future and the sadness of the past events and reduces the quality patients' life. Thus, one of the basic principles of spiritual care is strengthening the belief in God's mercy for creating hope. Spiritual counselor must create optimism to the future by reinforcing the belief in the God's power [43]. The courage to face with the crisis of disease must be created, by "trusting in God" and "entrusting things to God. Religious spirituality gives meaning to human life through the relationship with God and modifies other human communication [44]. The belief in life after death, being in the "safe haven of God's love" and accepting the subject of death as rebirth in another world, makes it possible for the patient to go through the last stages of the illness without fear of death [38].

In a descriptive study, parents' attitudes toward spiritual and religious interventions of physicians were investigated. The parents' belief system was asked to understand their spiritual needs. $49 \%$ of all respondents and $62 \%$ of those who called themselves moderate or highly religious, stated that their beliefs influenced their decisions about child's medical care. Physician consultation with parents in spiritual care would improve the conditions for treatment of critically ill children [45]. In the present study, considering the necessity of community-based health services the coordination of therapeutic measures with patient's beliefs and family culture were emphasized and the parents' willingness to care were respected which was emphasized by the World Health Organization (WHO) at the Edinburgh conference [46].

\section{Limitations}

Providing spiritual counseling is a teamwork but, in this research, only a nurse, with the help of educational software and social network, taught spiritual skills.

\section{Suggestions}

It is recommended that in future research, for chronic and cancer patients, spiritual empowerment with multimedia educational method performed by the spiritual team.

\section{Conclusion}

The results showed that spiritual empowerment program based on sound heart model was effective on spiritual health of parents. The use of this educational method was effective, so using educational software is recommended.

\section{Acknowledgments}

We would like to sincerely thank and appreciates the Deputy of Research and Technology (Clinical Research Development Unit) of Baqiyatallah hospital for their supports and advices, the Pediatrics staff of Children's Medical Center and all family who collaborated in conducting this study. 


\section{References}

1. Dawson S, Charles AK, Bower C, de Klerk NH, Milne E (2015) Risk of cancer among children with birth defects: a novel approach. Birth Defects Research Part A: Clinical and Molecular Teratology 103(4): 284291.

2. Kaatsch P (2010) Epidemiology of childhood cancer. Cancer Treat Rev 36(4): 277-285.

3. Ward E, DeSantis C, Robbins A, Kohler B, Jemal A (2014) Childhood and adolescent cancer statistics, 2014. CA: a cancer journal for clinicians 64(2): 83-103.

4. Ji Q, Currin-McCulloch JA, Zhang A, Streeter CL, Jones BL, et al. (2018) Assessing the Needs of Parents of Children Diagnosed with Cancer in China: A Psychometric Study Developing a Needs Assessment Tool. Journal of Pediatric Oncology Nursing 35(1): 6-15.

5. Pelland-Marcotte MC, Hwee J, Pole JD, Nathan PC, Sung L (2019) Incidence of infections after therapy completion in children with acute lymphoblastic leukemia or acute myeloid leukemia: a systematic review of the literature. Leukemia \& lymphoma 60(9): 1-11.

6. Asadzandi M (2019) Spiritual Care Guidelines for Chronic and Cancer Patients (Counselors Guide). Publisher: Resaneh-takhassosi.

7. Farahani AS, Rassouli M, Salmani N, Mojen LK, Sajjadi M, et al. (2019) Evaluation of Health-Care Providers' Perception of Spiritual Care and the Obstacles to Its Implementation. Asia-Pacific Journal of Oncology Nursing 6(2): 122.

8. Doumit MA, Rahi AC, Saab R, Majdalani M (2019) Spirituality among parents of children with cancer in a Middle Eastern country. European Journal of Oncology Nursing 39: 21-27.

9. Asadzandi M (2018a) Guidebook of spiritual care for patient's family. Publisher: Resaneh -takhassosi.

10. Khanjari S, Oskouie F, Eshaghian Dorche A, Haghani H (2013) Quality of life in parent of children with leukemia and its related factors. Iran Journal of Nursing 26(82): 1-10.

11. Ruiz J, Glade Bender JL, Oberg J, Cohn E, Levine J (2014) Knowledge, attitudes, and beliefs of parents toward whole-genome sequencing in pediatric cancer. American Society of Clinical Oncology 32(15).

12. Williams PD, Williams KA, Williams AR (2014) Parental caregiving of children with cancer and family impact, economic burden: nursing perspectives. Issues in comprehensive pediatric nursing 37(1): 39-60.

13. Asadzandi M (2018b) Spiritual Empowerment Program Based on Sound Heart Model in the Cancerous Children's Family. Annals of Nursing Research and Practice 3(1): 1026.

14. Purow B, Alisanski S, Putnam G, Ruderman M (2011) Spirituality and pediatric cancer. Southern medical journal 104(4): 299-302.

15. Asadzandi M, Shahrabi Farahany S, Abolghasemi H, Saberi M, EbadiA (2020) Effect of Sound Heart Model- based spiritual counseling on stress, anxiety and depression of parents of children with cancer. Iran J Ped Hematol Oncol 10(2): 96-106.

16. Pinquart M, Featured A (2018) Depressive Symptoms in Parents of Children with Chronic Health Conditions: A Meta-Analysis. Journal of pediatric psychology 44(2): 139-149.

17. Zolfaghari M, Asgari P, Bahramnezhad F, AhmadiRad S, Haghani H (2015) Comparison of two educational methods (family-centered and patientcentered) on hemodialysis: Related complications. Iranian journal of nursing and midwifery research 20(1): 87-92.

18. Rezai Asl H, Seyyed Mazhari M, Pishgooi SAH, Alhani F (2017) The Effectiveness of "Family-Centered Empowerment Model" on the Treatment Adherence of Patients with Type II Diabetes and Heart Disorder Admitted to AJA Hospitals, During Year 2015. Military Caring Sciences Journal 4(1): 58-69.

19. Vahedian-Azimi A, Miller AC, Hajiesmaieli M, Kangasniemi M, Alhani F, et al. (2016) Cardiac rehabilitation using the Family-Centered
Empowerment Model versus home-based cardiac rehabilitation in patients with myocardial infarction: a randomised controlled trial. Open heart 3(1): e000349.

20. Dehbashi F, Sabzevari S, Tirgari B (2015) The relationship between spiritual well-being and hope in Hemodialysis patients referring to the Khatam Anbiya hospital in Zahedan 2013-2014. Medical Ethics Journal 9(30): 77-97.

21. Saeidi Taheri Z, Asadzandi M, Ebadi A (2014) The effect of spiritual care based on Ghalbe Salim model on the sleep quality of the patients with coronary artery disease. Iran J Critical Care Nursing 7(2): 94-103.

22. Abolghasemi H, Asadzandi M (2018) Reinforcing faith, the main care and method of maintaining and improving the spiritual health of patients and clients. Health Promotion Quarterly Journal of the Medical Sciences of the Islamic Republic of Iran - Special Issue for Spiritual Health 1(1): 39-49.

23. Tazakori Z, Hasankhani H, Mohamadi E, Valizadeh S (2013) Process of spiritual care learning in Iranian nursing students: A grounded theory study. The journal of urmia nursing and midwifery faculty 11(1): 51-63.

24. Khanjari S, Seyedfatemi N, Borji S, Haghani H (2014) Effect of coping skills training on quality of life among parents of children with leukemia. J Hayat 19(4): 15-25.

25. Akbarpour Mazandarani H, Asadzandi M, Saffari M, Khaghanizadeh M (2017) Effect of Spiritual Care Based on Sound-Heart Consulting Model (SHCM) on Spiritual Health of Hemodialysis Patients. IJCCN 10(4): 1-6.

26. Asadzandi M (2019) Sound Heart, Spiritual Health from the perspective of Islam. J Relig Theology 2(4): 22-29.

27. Asadzandi M (2017) Sound Heart: Spiritual Nursing Care Model from Religious Viewpoint. J Relig Health 56(6): 2063-2075.

28. Asadzandi M (2018) An Islamic religious spiritual health training model for patients. J Relig Health 59: 173-182.

29. Zafarian Moghaddam E, Behnam Vashani HR, Reihani T, Namazi Zadegan S (2016) The Effect of Spiritual education on depression, anxiety and stress of caregivers of children with leukemia. Journal of Torbat Heydariyeh University of Medical Sciences 4(1): 1-7.

30. Rajabi R, Forozy M, Fuladvandi M, Eslami H, Asadabady A (2016) The effect of family-centered empowerment model on the knowledge, attitudes and self-efficacy of mothers of children with asthma. Journal of Nursing Education 5(4): 41-50.

31. Rezaie Shahsavarloo Z, Lotfi M, Taghadosi M, Mousavi M, Yousefi Z (2015) Relationship between components of Spiritual well-being with hope and life satisfaction in elderly cancer patients in Kashan, 2013. Iranian Journal of Geriatric Nursing 1(2): 43-54.

32. Abolghasemi H, Asadzandi M (2019) How Spiritual Health Affects Other Dimensions of Health. journal of culture and health promotion 3(2): 164-174.

33. Murray SA, Kendall M, Grant E, Boyd K, Barclay S, et al. (2007) Patterns of social, psychological, and spiritual decline toward the end of life in lung cancer and heart failure. Journal of pain and symptom management 34(4): 393-402.

34. Freeman G (2011) Spirituality and servant leadership: A conceptual model and research proposal. Emerging Leadership Journeys 4(1): 120140 .

35. Bernard M, Strasser F, Gamondi C, Braunschweig G, Forster M, et al. (2017) Relationship between spirituality, meaning in life, psychological distress, wish for hastened death, and their influence on quality of life in palliative care patients. Journal of pain and symptom management 54(4): 514-522.

36. Asayesh H, Zamanian H, Mirgheisari A (2013) Spiritual Well-being and religious coping strategies among hemodialysis patients. Iranian Journal of Psychiatric Nursing 1(1): 48-54.

37. Salsman JM, Pustejovsky JE, Jim HS, Munoz AR, Merluzzi TV, et al. (2015) A meta-analytic approach to examining the correlation between 
religion/spirituality and mental health in cancer. Cancer 121(21): 37693778.

38. Asadzandi M (2019) Prevention of Death Anxiety by Familiarity with the Concept of Death. Journal of Preventive Medicine and Care 2(4): 23-30.

39. Asadzandi M, Taghizade KaratiK, Tadrisi SD, Ebadi A (2011) Effect of Prayer on Severity of Patients Illness in Intensive Care Units. Iranian Journal of Critical Care Nursing 4(1): 1-6.

40. Asadizandi M, Saayari R, Sanayi Nasab H, Ebadi A (2018) The Influence of Islamic Ritual Training on Primary Sleep Disorders among Nurses. Journal of Psychiatry and Behavioral Health Forecast 1(1): 11-18.

41. Rezaei M, Fatemi NS, Givari A, Hoseini F (2017) Relation between prayer activity and spiritual well-being in cancer patients undergoing chemotherapy. Iran Journal of Nursing 20(52):51-61.

42. Mohebbifar R, Pakpour AH, Nahvijou A, Sadeghi A (2015) Relationship between spiritual health and quality of life in patients with cancer. Asian Pac J Cancer Prev 16(16): 7321-7326.

ISSN: 2574-1241

DOI: 10.26717/BJSTR.2021.33.005367

Minoo Asadzandi. Biomed J Sci \& Tech Res

(c) (P) This work is licensed under Creative

Submission Link: https://biomedres.us/submit-manuscript.php
43. Mazandarani H, Asadzandi M, Saffari M, Khaghanizadeh M (2018) The Effect of Spiritual Care Based on Sound Heart Model on Quality of Life in Hemodialysis Patients. Journal of Psychiatry and Behavioral Health Forecast 1(1): 1-6.

44. Tabatabaee M (2019) Tfsyr Al-Mizan Qom: Office of Publications.

45. Arutyunyan T, Odetola F, Swieringa R, Niedner M (2018) Religion and spiritual care in pediatric intensive care unit: parental attitudes regarding physician spiritual and religious inquiry. American Journal of Hospice and Palliative Medicine 35(1): 28-33.

46. Asadzandi M (2018) Designing Inter Professional Spiritual Health Care Education Program for Students of Health Sciences. Journal of Nursing and Patient Health Care 1(1): 1-7.

$\begin{array}{ll}\text { BIOMEDICAL } & \text { Assets of Publishing with us } \\ \text { RESEARCHES } & \text { Global archiving of articles } \\ \text { - Immediate, unrestricted online access } & \text { - Rigorous Peer Review Process } \\ & \text { - Authors Retain Copyrights }\end{array}$

